\title{
Tuberculosis in Early Infancy: Rare in Today's World
}

\author{
Thakur J', Rai B' ${ }^{2}$ Singh RR ${ }^{3}$, Ghosh S $^{4}$, Gyawali P5
}

\begin{abstract}
Tuberculosis in early infancy was not so common earlier also and has become rare these days. Since the disease is occasionally encountered, pediatricians should suspect tuberculosis in infants not responding to standard therapy. Here we report a case of three months old female who had presented with complaints of fever for two months, cough for one and half months and difficulty breathing for seven days and was being treated in line of bacterial pneumonia without improvement. She was found to be mycobacterium positive and was treated with anti-tubercular therapy leading to improvement and discharge. So, though rare, it is important to consider tuberculosis even in early infancy not responding to standard antibiotic therapy.
\end{abstract}

Key words: Tuberculosis, Infant, Diagnosis

\section{Introduction}

$\mathrm{T}$ he epidemiology of TB in young children ( $<5$ years old), a vulnerable population is not well understood ${ }^{1}$. Children account for $10 \%$ of TB cases annually ${ }^{2}$ but the incidence of childhood TB in Nepal is reported only to be $2 \%$ of total cases of $\mathrm{TB}^{3}$. Tuberculosis in early infancy is not so common. The diagnosis of tuberculosis is more difficult in children, especially because symptoms are subtle ${ }^{4}$. Infants and young children are at much more risk of developing disseminated infection and tubercular meningitis, with high mortality. Publications have been there to describe tuberculosis (meningitis, pulmonary and others) in infancy but these are mostly in last decade ${ }^{5,6,7}$. In recent years there have been very few reports describing tuberculosis in infancy $8,9,10$.

\section{The Case}

A three month old female infant, immunized with BCG vaccine and from low socioeconomic background with normal birth and perinatal history, presented with complaints of fever for two months, cough for one and half months and difficulty breathing for seven days. Initially she was treated by a local heath personnel with oral amoxicillin + clavulanic acid and later at three other centers with injectable antibiotics for pneumonia in various combinations (ceftriaxone, vancomycin, amikacin, piperacillin + tazobactam, meropenem) without any improvement rather gradual deterioration. Various investigations
${ }^{1}$ Dr. Jitendra Thakur, MBBS. MD, Assistant Professor, ${ }^{2} \mathrm{Dr}$. Basant Rai, MBBS. MD, Assistant Professor, ${ }^{3} \mathrm{Dr}$. Rupa Rajbhandari Singh, MBBS. MD, Professor, ${ }^{4} \mathrm{Dr}$. Sohini Ghosh, MBBS. Junior Resident (MD), ${ }^{5} \mathrm{Dr}$. Pratyush Gyawali, MBBS. Junior Resident (MD). All from the Department of Pediatrics and Adolescent Medicine, BPKIHS, Dharan, Nepal.

\section{Address for correspondence \\ Dr. Jitendra Thakur \\ E-mail: jthakur797@gmail.com}

\section{How to cite}

Thakur J, Rai B, Singh RR, Ghosh S, Gyawali P. Tuberculosis in Early Infancy: Rare in Today's World. J Nepal Paediatr Soc 2018;38(2):143145.

doi: http://dx.doi.org/10.3126/jnps.v38i2.19329

This work is licensed under a Creative Commons Attribution 3.0 License.

\section{(c) (i)}


were done outside but no tuberculosis workup was done. X-ray was done but was not brought. There was no past medical illness, history of tuberculosis or chronic cough in family and relatives and history of consanguinity or sibling death.

On examination, she was tachypnoeic with respiratory rate of 64/minute with subcostal retractions. On auscultation crepitation was present all over the chest. Other systems were within normal limit and there was no palpable lymph nodes.

There was anaemia with haemoglobin of $7.4 \mathrm{gram} /$ dl but other blood parameters were within normal limit. Chest $\mathrm{x}$-ray showed increased peri-hilar opacity and patchy opacity in bilateral lung fields as shown in Figure 1.

Patient was started on ceftriaxone and vancomycin . Manteux test was done with five units of purified protein derivative (PPD) and gastric aspirate (GA) was sent for acid fast bacillus (AFB) staining. Patient was kept under mechanical ventilation for severe respiratory distress on second day of admission. No induration was noted in manteux test. First sample of GA for AFB was negative but second sample showed $3+$ AFB. Patient was started on anti-tubercular therapy (ATT) with isoniazid $(H)$, rifampicin $(R)$, pyrazinamide $(Z)$ and ethambutol (E) along with pyridoxine. Gene xpert showed no multidrug resistant (MDR) TB and CSF picture was not suggestive of TB meningitis. Other newer modalities for the diagnosis of tuberculosis was not required because mycobacterium was detected on GA. Possible reasons for not noting induration in manteaux test were that recent infection with mycobacterium (8-10 weeks) may have false negative reaction and low immunity in infancy.

Because of the prolonged duration of illness and not responding to antibiotics, other etiological diagnosis for pneumonia except for bacterial like fungal, atypical organism or resistant bacterial infection were also thought. But since blood culture didn't show growth and mycobacterium was seen in GA, the diagnosis was clear.

Just after two days of ATT respiratory distress improved and patient was extubated after seventytwo hours of mechanical ventilation. Parents though asymptomatic were screened for tuberculosis and were negative. Patient was discharged after seven days of hospital stay and chest xray showed improvement within a week as in Figure 2. Patient followed up at two months of ATT. There was no subjective complaint and AFB in GA was not seen and patient was shifted to continuation phase with HR.

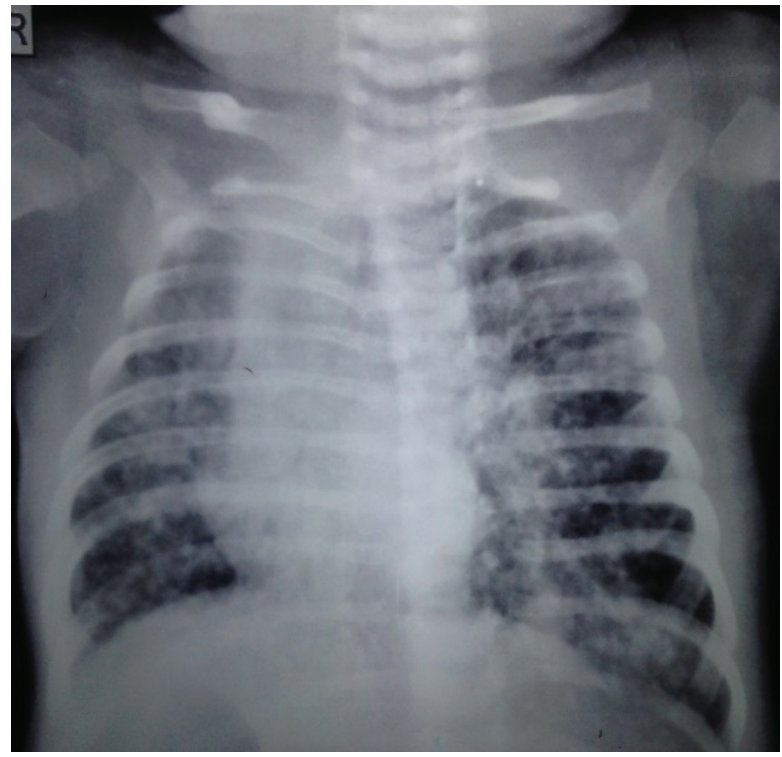

Fig 1: Chest X-ray showing increased perihilar opacity and patchy opacity in bilateral lung fields.

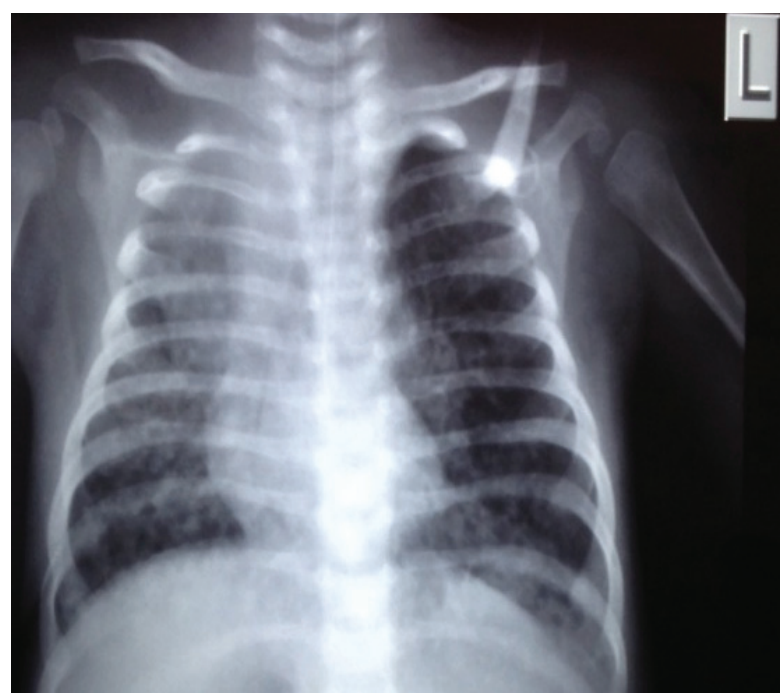

Fig 2: Chest X-ray showing improvement in one week treatment

\section{Discussion}

A prerequisite for the early diagnosis of tuberculosis in childhood is a high index of suspicion. At no age is this more important than during infancy when the consequences of a missed or delayed diagnosis are likely to be considerably more serious than at a later age. Dhua AK et $\mathrm{al}^{8}$ in 2011 described an infant of thirtyfour days who presented with haematuria and was later diagnosed as congenital renal TB but ours was a case of acquired pulmonary TB. Dempers et $\mathrm{al}^{9}$ in 2010 described a case of four months infant initially diagnosed as sudden unexpected death in infancy but later came out to be primary progressive TB on autopsy but in our case patient survived despite carrying symptoms for two months. Peterson RR et $\mathrm{al}^{10}$ in 2012 described a case of spinal tuberculosis in an infant of ten months old with 
maternal urinary tuberculosis but in our case patient was 3 months old without TB in mother. Thus, though rare, tuberculosis in infancy does exist and without high index of suspicion these cases are likely to be missed leading to poor outcome of the case. Timely diagnosis and treatment will have good outcome even in infants.

\section{References}

1. Jain SK, Ordonez A, Kinikar A, Gupte N, Thakar M, Mave V, Jubulis J, Dharmshale S, Desai S, Hatolkar $\mathrm{S}$, Kagal A. Pediatric tuberculosis in young children in India: a prospective study. Biomed Res Int 2013;2013;783698. DOI:10.1155/2013/783698

2. Sudeep Uprety, Bipul Lamichhane; Global Attention on Tuberculosis: Summary of Global TB Report 2016; Health Research and Social Development Forum (HERD); www.herd.org.np

3. Annual report 2014, National Tuberculosis Program, Ministry of Health and Population, Nepal.

4. Choueiry E, El Haber C, Diab S, Torbey PH, Gerbaka B. Primary Pulmonary Tuberculosis in Infancy With Respiratory Syncytial Virus Infection: A Case Report. Int J Clin Pediatr 2016;5(3-4):54-5. DOI: https://doi. org/10.14740/ijcp261w

5. Maltezou HC, Spyridis P, Kafetzis DA. Tuberculosis during infancy. Int J of Tuber Lung Dis 2000;4(5):414-9.

\section{Conclusion}

Children of any age group presenting with atypical symptoms or not responding to standard treatment should be evaluated for tuberculosis.

6. Tung YR, Lai MC, Lui CC, Tsai KL, Huang LT, Chang YC, Huang SC, Yang SN, Hung PL. Tuberculous meningitis in infancy. Pediatr Neuro/2002;27(4):262-66. DOI: https://doi.org/10.1016/S0887-8994(02)00431-9

7. Oberg CN, Hedemark L. Tuberculosis in infancy: a case report. Clin Pediatr 1991;30(8):498-501. DOI: https://doi.org/10.1177/000992289103000808

8. Dhua AK, Barkar N, Ghosh V, Aggarwal SK. Renal tuberculosis in infancy. J Indian Assoc Pediatr Surgeons 2011;16(2):69-71. DOI: 10.4103/09719261.78136

9. Dempers J, Sens MA, Wadee SA, Kinney HC, Odendaal HJ, Wright CA. Progressive primary pulmonary tuberculosis presenting as the sudden unexpected death in infancy: a case report. For Sci Int 2011;206(1-3):e27-30. DOI: https://doi.org/10.1016/j. forsciint.2010.07.018

10. Peterson RR, Agarwal I, Gibikote S. Spinal tuberculosis in an infant associated with maternal urinary tuberculosis. Published quarterly by the Tuberculosis Association of India 2012;59:168-70. 